\title{
The Wheat Problem
}

THE Twentieth Report of the Imperial Economic Committee, originally intended for presentation at the Ottawa Conference in 1931, which was eventually postponed, has been issued in the form of a survey,* without recommendations, of the present wheat position, with an analysis of the chief causeseconomic, technical, social, and political-contributing thereto, together with indications as to which are in all probability temporary and which of a more permanent character. The fact that over vast areas of land the growing of wheat, the primary foodstuff of the world, does not repay the cost of production is a problem of the first magnitude for the Empire and for the world in general, and it is evident that such a situation has been brought about by the interaction of a number of complex causes.

In the report a statistical treatment is made of the changes in price, production, acreage, yield, and international trade that have taken place since 1920, special attention being paid to the later years of the period. Figures for Russia are excluded on account of their uncertainty and the exceptional position occupied by Great Britain during the years under consideration.

Since 1921 the trends of prices of wheat and general commodities have been very similar; this suggests that the changes in wheat prices are not solely attributable to causes peculiar to wheat production or marketing. Production, although in excess of effective demand in recent years, is actually lower than that normally expected from the pre-War trend, so that the term 'over-production' is a relative one only. The re-entry of Russia into the export trade, however, has done much to intensify the disparity between supply and demand. As a result, at the end of the crop year 1930-31, curtailment in wheat production was taking place in all the principal

- Reports of the Imperial Economic Conference. Twentieth Report : The Wheat Situation, 1931. Pp. 121. (London: H.M. Stationery Office, 1932.) $6 d$. net. exporting countries except Canada and Russia. The expansion which had occurred during the previous nine years was due to an increase in area harvested, rather than to any changes in the average yield per acre, which for the world as a whole has not shown much variation. Biological and, particularly, mechanical improvements in the methods of wheat production during the post-War period have had far-reaching economic consequences, for the result has been an increased output at a lower cost of production of a commodity for which a corresponding increase in consumption was not obtained.

Comparison is made between the policies adopted by certain important exporting and importing countries, and, almost throughout Europe, State action has been taken with the view of raising internal wheat prices in the interest of local producers. The most significant and, at the same time, the most uncertain feature of the present situation, however, is Russia. The existence of a wheat-producing country and potential exporter of the magnitude of Russia, the policy of which is not directly related to the international level of wheat prices, introduces completely new economic considerations into the question and complicates the task of assessing the world's situation.

The outlook for the season 1931-32, as summarised by the International Institute of Agriculture, indicates that the total world's production, including Russia, is, on the whole, insufficient to cover the requirements of consumption, so that it will be necessary to draw upon the accumulated stocks which continue to depress the market, but, nevertheless, it is estimated that they will still remain heavy at the end of the current crop year.

The wheat problem is, however, fundamentally a general problem, and the removal of the obstacles which to-day impede the recovery of industrial life would go a long way towards bringing about an improvement in the wheat situation.

\section{Recent Excavations in British Honduras}

THE report of the first and second Marshall Field Archæological Expeditions to British Honduras * serves to point the moral that, in archæological investigation, it by no means follows that the outstanding site or the sensational discovery in the long run makes the most illuminating contribution to knowledge of the culture of the people under investigation.

The settlements explored by these expeditions in 1928 and 1929 were situated in a peripheral area of Maya culture, in which neither exceptional develop. ment nor an advanced standard in the arts of life could be expected; while in themselves they were not of sufficient importance to justify inclusion even in the rank of fourth class sites. Yet, being in part residential, they give a truer view of the life and customs of the people than do more imposing ceremonial centres. The material they have yielded will constitute a considerable contribution toward what is much needed, namely, the formulation of an ordered sequence of pottery types and styles within a defined cultural area, which will serve as a basis for systematic and intensive study of the cultural history of circum. jacent regions in an ever-widening circle. Toward this a beginning has now been made in the investigations undertaken, or projected, by the Carnegie Institu-

" "Archæological Investigations in the Southern Cayo District, British Honduras." By J. Eric Thompson. Field Museum of Natural History, Publication 301. Anthropological Series, vol. 17, No. 3. tion of Washington at Uaxactun (Guatemala) and the Field Museum of Chicago in north-central Honduras.

The sites investigated by the two expeditions, of which Mr. Eric Thompson was the leader, are situated in the Cayo district of British Honduras, on the western frontier, where it borders on Guatemala. The actual site of the excavations was twenty-five miles south-east of the town of El Cayo in the neighbourhood of the Mountain Cow Water Hole. Except for a scarcity of water, the site was admirably adapted to Maya settlement, having an abundance of game and a salubrious air owing to its height. In fact, these settlements are the highest cities in the "Old Empire' area, Hatzcap Ceel, described in this report, being probably as much as $2250 \mathrm{ft}$. above sea-level. The country being very broken, the inhabitants were practically cut off from cities to the south, such as Pusilha and Lubaantun, though only forty miles away. To the west and north-west-to Ixkun, about thirtythree miles, and Ucanal, twenty-seven miles awaythe country was easily traversed. Although it is not known with certainty which tribes inhabited this area when the Spaniards came, it is. probable either that they were Mopans, who are known to have occupied the country immediately to the west, or were closely allied to that people. It is suggested tentatively that in ancient times these Mountain Cow Water Hole area cities were inhabited by Chol-speaking Mayas.

No. 3259, VoL. 129] 
Four groups of sites within a two-mile radius of the Mountain Cow Water Hole area were excavated. Of these, two, Hatzcap Ceel and Cahal Pichik, were ceremonial centres and two, Tzimin Kax and Cahal Cunil, were residential sites.

The two ceremonial centres flourished at the close of Cycle 9 and the beginning of Cycle 10 in Maya dating. Evidence for this is afforded by two dated monuments, of which the dates correspond to A.D. 835 and A.D. 910. There is evidence also of a succession of construction periods in the superposition of buildings, though not all these must be taken to represent distinct culture phases. The pyramids were found to be in a collapsed condition. Each of the ceremonial sites possibly had a ball court between two pyramids. Most of the pyramids of the temple type yielded votive caches. The contents of these caches were generally uniform in character, seven of the ten found containing characteristic small figurines of jade, slate, or shell. Other offerings were jade and small objects, including a worked flint of eccentric form with three arms, or points, two lobster-claw-shaped and one tau-shaped, In five of the seven caches containing figurines were containers in the form of a barrel-shaped cylindrical urn. One of the offerings is a mask which is undoubtedly the finest jade object yet found in British Honduras. It is now in the British Museum. A mirror of iron pyrites was found at Hatzcap Ceel, but the remains of what was probably a second were too far corroded to permit of certain identification.

The evidence of the pottery showed that these two sites belong to the same general cultural area as Holmul, Yalloch, and Uaxactun-an area in which art, as exemplified in stone carving on altar and stelæ, did not fall far short of that of the larger cities of the Peten region in what is now Guatemala; but architecture and the ability to erect large carved stone monuments did not penetrate here until late in the Old Empire period. It would appear that the art of erecting large multiple vaulted buildings never reached the Mountain Cow Water Hole region.

The two residential sites, Tzimin Kax and Cahal Cunil, consist of a number of scattered plazas of small size, constructed on the tops of natural hillocks enlarged by piling around them masses of stone and rubble up to a height of three or four feet above the natural summit. The whole was then levelled up, and pyramidal square and low oblong mounds erected at the edge of the platform thus constructed. The platforms average twenty-five metres in each direction and are orientated within three or four degrees of true north. The outside walls were made of blocks of stone roughly faced but unsquared. The fill is of large limestone boulders and a small amount of rubble, but is loose. There is evidence that the platforms were reconstructed on several occasions.

A number of burials was associated with most of the plazuelas. This would be fully in accord with what we know of Maya practice. Bishop Landa says that it was cuistomary for the people of Yucatan to bury their dead under the house, and among the modern Maya, children are buried under the floors of the huts. It is to be noted that in a burial at Tzimin Kax a number of small crude pots were found in pairs, one being placed mouth downwards over the other. Three of these contained bones: in one the first, second, and third dactyls of a human hand, judging by its size, of a woman or adolescent; and in a second a single bone, which proved to be the second dactyl of a small adult's hand. Dr. Gann also records the finding of the terminal phalanx of "a Maya lady's little finger" from a burial near Progreso. The skeletal remains were in a bad state of preservation, but Prof. Elliot Smith reported on two skulls as showing marked antero-posterior deformation.

The two residential sites were evidently occupied for a longer period than the ceremonial centres. Reference to the classification made by Dr. Vaillant at Holmul shows that all four sites were oceupied in the period Holmul V., while the earlier period of Holmul I. is represented in burials at both the residential sites. At Cahal Cunil there is certain evidence which points to a still earlier period of 'pre-Holmul'. Pottery of the same type has been found at Uaxactun in conditions which point to its being earlier than Holmul I. It must be remembered that although this correspondence with Holmul is established in the Mountain Cow Water Hole area, it does not necessarily follow that in absolute dating the two are contemporary; the latter being a peripheral area, Holmul pottery may have reached it at a later date. It is clear that the sites were not occupied after the introduction of metal.

\section{Forecasts of Fisheries}

AEPORT of the activities of the various area committees of the International Council for the Exploration of the Sea has recently been published.* In small compass, it may be said to place before the publics of the different nations represented in the Council the aims and present achievements of marine investigation. Amongst a wealth of valuable and interesting material, the report of the Northern North Sea Committee deserves special mention, as recording a notable landmark in the history of fishery research.

In the work of this Committee, most attention is being given to the herring and the haddock-the two most important commercial fishes of the northern North Sea. As a result of this concentration of effort, there is being built up, slowly but surely, a very definite knowledge of the composition of the stocks of these two species which is of immediate value for an understanding of the fluctuations in the practical fisheries. Much still remains to be accomplished,

* Conseil Permanent International pour l'Exploration de la Mer. Rapports et procès-verbaux des réunions. Vol. 74 : Procès-verbaux
(Mars 1931). Pp. 203. (Copenhague : Andr. Fred. Host et fils, 1931.) (Mars 1931 .

No. 3259, VoL. 129] more particularly with regard to the correlation of these fluctuations in the year classes of fish entering the marketable stocks with the successive changes in hydrographical and biological conditions in the sea.

Nevertheless, the work on the haddock has reached a stage when the yield of the North Sea haddock fisheries for eighteen months or two years ahead can be anticipated with great accuracy. Definite forecasts, made only experimentally as yet, have proved most satisfactory. For example, the general success of a forecast made in April 1929 at the scientific meeting of the International Fisheries Conference in London is cited. At that meeting it was stated that the fairly successful 1926 brood should, for most of its fourth year (1929), serve to provide catches just above normal. By the end of the autumn of that year, however, this brood should have made the greater part of its contribution to the catches. The 1927 brood had proved a failure, so catches would therefore be expected to sink below normal from late autumn 1929 to well on in 1930. But about August of the latter year there should take place a marked increase in the catches owing to the upgrowth of the highly successful 1928 